\title{
EVALUATION OF THE FREE VOLUME THEORY TO PREDICT MOISTURE TRANSPORT AND QUALITY CHANGES DURING BROCCOLI DRYING
}

\author{
X.Jin ${ }^{1}$, R.G.M. van der $\mathrm{Sman}^{2}$, A.J.B. van Boxtel ${ }^{1}$ \\ ${ }^{I}$ System and Control Group, Department of Agrotechnology and Food Science, \\ Wageningen University, P.O. Box 17, 6700AA, Wageningen, The Netherlands \\ Tel: +31(0)317482014, E-mail:xin.jin@wur.nl \\ ${ }^{2}$ Food Process Engineering Group, Department of Agrotechnology and Food Science, \\ Wageningen University, P.O. Box 8129, 6700EV, Wageningen, The Netherlands
}

\begin{abstract}
Moisture diffusion in porous broccoli florets and stalks is modeled by using the free volume and Maxwell-Eucken theories. These theories are based on the mobility of water and show the variation of the effective diffusion coefficient for a wide range of temperatures and moisture content of the product during drying. Mass and heat transport, shrinkage and vitamin $\mathrm{C}$ degradation during drying of broccoli are simulated by a spatial model. The effective diffusion coefficient varies strongly with product moisture content and temperature. Vitamin $\mathrm{C}$ degradation is strong at moisture contents below $4 \mathrm{~kg}$ water per kg dry matter.
\end{abstract}

Keywords: broccoli drying, moisture transport, spatial model, free volume theory, quality changes

\section{INTRODUCTION}

Since a low product moisture content allows a safe storage of food products over a long period, drying has gained an important position in the food industry. Water removal is the main function of drying, but at the same time quality changes will take place. For example, changes in shape, texture, colour, and deterioration of nutritional components occur during drying. As quality becomes a more and more important aspect of dried products, preservation of such qualities and minimization of deterioration are more essential.

Broccoli is a common vegetable for most families, not only because of the taste but also because of the components with nutritional value and components that contribute to health (e.g. vitamin $\mathrm{C}$ and glucosinolates). However, as these components are temperature sensitive, they may deteriorate during drying. Thus low and moderate temperatures are necessary for drying. Furthermore, the changes in quality depend on the local, time varying, moisture content and temperatures in the product rather than the average moisture content. With dynamic distributed models the quality and moisture content during the drying process can be predicted. These models are also essential to optimize the product quality.

To predict and to optimize the quality it is necessary to know the concentration and temperature profiles in the product as a function of time. In drying there are normally two main drying periods: the constant rate period and the falling rate period. Mulet et al.(1999) showed that for drying of broccoli, at high air velocity, drying is controlled by diffusion.

For diffusion controlled drying, Fick's second law is usually applied to describe the mass transport. The effective diffusion coefficient which is estimated from drying data represents the overall mass transport of water in the material to be dried. The most common approach to describe the temperature dependency of the effective diffusion coefficient is the Arrhenius equation (Bon, 1997, Mulet et al. 1999). Since the Arrhenius equation is an empirical equation, it has limitations in its application for complex systems such as foods. At temperatures above the product glass transition temperature, state transformations occur, and as a result the diffusive behaviour will change. The Arrhenius equation is then not accurate enough to predict diffusion.

As an alternative, the effective diffusion coefficient can be predicted from the free volume theory (FloryHuggins), which is used for diffusion of polymer solutions (Vrentas, 1977, Vrentas, 1994). The main idea of this theory is that the free volume between polymer chains (voids) is the limiting factor for diffusion. Water molecules move between such voids with acquired sufficient energy to overcome forces attracting them to neighbouring molecules. (Hong, 1996, Nasrabad, 2005). The free volume theory is 
based on physical properties and involves the glass and state transition parameters of the polymeric chains in food. By calculating the diffusion coefficient according the free volume theory, the drying rate can be predicted precisely over a large temperature and moisture content range. A recent example on the moisture migration of trehalose solution drying (He, 2008) introduces this theory for drying of bio-products.

This work applies the free volume theory on broccoli drying to describe moisture diffusion and drying rate for broccoli. The result is compared with the common diffusion model which uses the Arrhenius equation. Besides, the moisture distribution in the product will be shown with a spatially distributed model and the effect on product quality is determined.

\section{THEORY AND MODELING}

\section{Basic balance equations and boundary conditions}

The mass balance equation according to Fick's second law is:

$$
\frac{\partial W}{\partial t}=D_{e f f} \frac{\partial^{2} W}{\partial r^{2}}
$$

With W (kg water per $\mathrm{kg}$ dry matter) the moisture content, $\mathrm{D}_{\text {eff }}\left(\mathrm{m}^{2} \cdot \mathrm{s}^{-1}\right)$ the effective diffusion coefficient.

This equation is applied for florets and stalks by using respectively spherical and cylindrical coordinates (Bon (1997), Simal (1998)).

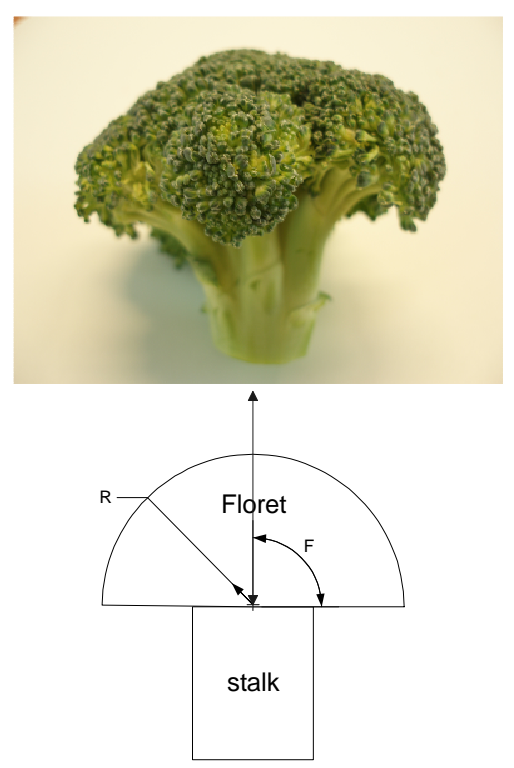

Fig 1 Top: the natural structure of broccoli, Bottom: the applied model structure for broccoli

As shown in Fig 1 the natural structure of broccoli is translated into a form for spatial calculations of moisture and temperature. The floret is characterised by a high porosity.

Similarly, the heat transport follows Fourier's law:

$$
\rho_{p} C_{p p} \frac{\partial T}{\partial t}=\lambda \frac{\partial^{2} T}{\partial r^{2}}
$$

Again spherical and cylindrical coordinates are applied for broccoli florets and broccoli stalks respectively, with $\lambda\left(\mathrm{W} \cdot \mathrm{K}^{-1} \cdot \mathrm{m}^{-1}\right)$ as the thermal conductivity, $\mathrm{C}_{\mathrm{pp}}\left(\mathrm{J} \cdot \mathrm{kg}^{-1} \cdot \mathrm{K}^{-1}\right)$ the specific heat of the drying material, and $\rho_{p}\left(\mathrm{~kg} \cdot \mathrm{m}^{-3}\right)$ the product density.

For the surface where $\mathrm{r}=\mathrm{R}$, the boundary condition for equation (1) is given by:

$$
k_{c}\left(C_{\text {surface }}-C_{\text {air }}\right)=D_{\text {eff }} \rho_{p} \frac{\partial W_{r=R}}{\partial r}
$$

$\mathrm{k}_{\mathrm{c}}\left(\mathrm{m} \cdot \mathrm{s}^{-1}\right)$ is the mass transfer coefficient, $\mathrm{C}_{\text {surface }}$ $\left(\mathrm{kg} . \mathrm{m}^{-3}\right)$ the vapor concentration at the product surface, and $\mathrm{C}_{\text {air }}\left(\mathrm{kg} . \mathrm{m}^{-3}\right)$ the vapor concentration in the air. This equation indicates that the liquid flux to the surface equals to the vapour flux from the surface to the bulk drying air.

Similarly, the boundary conditions for the heat balance equation (2) at the surface with $r=R$ is:

$$
\begin{aligned}
& h\left(T_{\text {air }}-T_{\text {surface }}\right)=\Delta H_{\text {evp }} D_{\text {eff }} \rho_{p} \frac{\partial W_{(r=R)}}{\partial r}+\ldots \\
& \ldots-\lambda \frac{\partial T_{(r=R)}}{\partial r}
\end{aligned}
$$

with $\mathrm{h}\left(\mathrm{W} \cdot \mathrm{m}^{-2} \cdot \mathrm{K}^{-1}\right)$ the heat transfer coefficient, $\Delta H_{\text {evp }}\left({\left.\mathrm{J} . \mathrm{kg}^{-1}\right)}^{-2}\right.$ the latent heat for evaporation. The term $\Delta H_{e v p} D_{e f f} \rho_{p} \frac{\partial W_{r=R}}{\partial r}$ indicates the amount of energy required to evaporate the liquid flux at the product surface.

For the centre of the product $(r=0)$, it is assumed that there is no mass and heat transfer over that surface of the drying product. Thus:

$$
\frac{\partial W_{r=0}}{\partial r}=0 \text { and } \frac{\partial T_{r=0}}{\partial r}=0
$$

Effective Diffusion Coefficient based on Arrhenius Theory

For many products an Arrhenius equation is used for the temperature dependency of $\mathrm{D}_{\text {eff }}$ with

$$
D_{\text {eff }}=D_{0} \exp \left(-\frac{E_{a}}{R T}\right)
$$

For the cylindrical part of broccoli (stalks), Simal et al. (1998) gives the equation: 
$D_{\text {eff }}=1.746 \times 10^{-5} \exp \left(\frac{-26155}{R T}+1.383 \times 10^{-2} W\right)$

For the hemispherical part of broccoli (florets), Bon and Simal et al. (1997) gives the equation:

$$
D_{\text {eff }}=8.04 \times 10^{-7} \exp \left(\frac{-20034.6}{R T}\right)
$$

W (kg water per kg dry matter) is the moisture content, $\mathrm{R}\left(8.314 \mathrm{~J} . \mathrm{K}^{-1} \cdot \mathrm{mol}^{-1}\right)$ is the gas constant and $\mathrm{T}(\mathrm{K})$ is the temperature. The Arrhenius equation is an empirical equation with its limitations in food products. Although it expresses the temperature dependency, above the glass transition temperature the state of the product changes, resulting in changed diffusion properties. Besides, the Arrhenius equation is not able to predict the diffusion in porous media.

Effective Diffusion Coefficient based on Free Volume Theory and Maxwell-Eucken Theory

In porous media the effective diffusion coefficient depends on the diffusion properties of the dispersed phase (air) and continuous phase (product). By using the Maxwell-Eucken relationship, the diffusion coefficient for water in products is composed from the diffusion coefficient of water in the continuous phase $\left(D_{c}\right)$ and in the dispersed phase $\left(D_{d}\right)$

$$
D_{e f f}=D_{c}\left(\frac{D_{d}+2 D_{c}+2(1-\varepsilon)\left(D_{d}-D_{c}\right)}{D_{d}+2 D_{c}-(1-\varepsilon)\left(D_{d}-D_{c}\right)}\right)
$$

For example, Bertola (1990) applied this theory in the carbon dioxide diffusion in tomatoes. In the case of moisture diffusion during broccoli drying, $D_{d}$ is the water vapour diffusion coefficient in the air and the values are available in literature. $D_{c}$ is the mutual diffusion coefficient of water molecules in food polymer chains. $\mathcal{E}$ is the porosity, which is low for the stalk and high for the porous floret

The water vapour diffusion coefficient in the air is given by Olek (2003):

$$
D_{d}=23 \times 10^{-6} \frac{98100}{P}\left(\frac{T}{273.15}\right)^{1.75}
$$

$\mathrm{P}$ is the pressure $(\mathrm{Pa}), \mathrm{T}$ the temperature $(\mathrm{K})$

The mutual diffusion coefficient of water molecules in food polymer chains is a combination of the selfdiffusivity of the water molecules $\left(D_{w}\right)$ and the self diffusivity of particles $\left(D_{s}\right)$. The mutual diffusivity for binary systems is given by the Darken relation (Hahn et al., 1986):

$$
D_{c}=Q\left[\phi \cdot D_{w}+(1-\phi) D_{s}\right]
$$

$$
Q=1-2 \chi \phi(1-\phi)
$$

$\varnothing(\%)$ is the volume fraction of the solid phase, Q (-) is a thermodynamic factor, and $\mathrm{X}(-)$ is the interaction parameter.

The self-diffusion coefficient of water $\left(D_{w}\right)$ follows the free volume theory, which considers physical properties of the product, such as water molecule mobility and the glass transition temperature. The free volume theory predicts the effective diffusion coefficient for a whole range of moisture contents and temperatures. Vrents (1977) showed the application for polymer diffusion system, while He et al. (2008) used this theory for moisture transport in sugars.

The water self diffusivity in a polymer matrix is given by:

$$
\begin{aligned}
& \ln \frac{D_{w}}{D_{0}}=\frac{\Delta E}{R T}+\ldots . \\
& -\frac{y_{1} \widehat{V}_{1}^{*}+\zeta y_{2} \widehat{V}_{2}^{*}}{y_{1}\left(K_{11} / \gamma\right)\left(K_{21}-T_{g, 1}+T\right)+y_{2}\left(K_{12} / \gamma\right)\left(K_{22}-T_{g, 2}+T\right)}
\end{aligned}
$$

With $\Delta \mathrm{E}\left(\mathrm{J} \cdot \mathrm{mol}^{-1}\right)$ the activation energy, $\mathrm{D}_{0}\left(\mathrm{~m}^{2} \cdot \mathrm{s}^{-1}\right)$ the pre-exponential factor, $\varsigma(-)$ the ratio between molar volume of solvent versus solute, $\mathrm{K}_{\mathrm{ij}}(\mathrm{K})$ as the free volume parameters, $T_{g, i}(K)$ is the glass transition temperature of component $\mathrm{i}, \mathrm{y}_{\mathrm{i}}(\%)$ is the mass fraction, and $\widehat{V}_{i}^{*}\left(\mathrm{ml}^{-\mathrm{g}^{-1}}\right)$ is the critical volume of component $\mathrm{i}$.

Free volume parameters of water are given by $\mathrm{He}$ et al. (2008) (See Table 1). The parameters for the solid matrix of broccoli are taken from sugars (e.g. sucrose and glucose) since they are the main components in broccoli. These parameters are summarized in Table 2.

Table 1: Free volume parameters of pure water

\begin{tabular}{|l|l|}
\hline \multicolumn{1}{|c|}{ Symbol } & \multicolumn{1}{c|}{ Value } \\
\hline$\widehat{V}_{1}^{*}\left(\mathrm{ml} \cdot \mathrm{g}^{-1}\right)$ & 0.91 \\
\hline $\mathrm{T}_{\mathrm{g}, 1}(\mathrm{~K})$ & 136 \\
\hline $\mathrm{D}_{0}\left(\mathrm{~m}^{2} \cdot \mathrm{s}^{-1}\right)$ & $1.39 \times 10^{-7}$ \\
\hline$\Delta \mathrm{E}\left(\mathrm{J} \cdot \mathrm{mol}^{-1}\right)$ & $1.98 \times 10^{3}$ \\
\hline $\mathrm{K}_{21}(\mathrm{~K})$ & -19.73 \\
\hline $\mathrm{K}_{11} / \gamma\left(\mathrm{m} \cdot \mathrm{L} \cdot \mathrm{g}^{-1} \cdot \mathrm{K}^{-1}\right)$ & $1.945 \times 10^{-3}$ \\
\hline
\end{tabular}

With 
Table 2: Free volume parameters of solid matrix of broccoli

\begin{tabular}{|l|l|}
\hline \multicolumn{1}{|c|}{ Symbol } & \multicolumn{1}{c|}{ Value } \\
\hline$\widehat{V}_{2}^{*}\left(\mathrm{ml} \cdot \mathrm{g}^{-1}\right)$ & 0.59 \\
\hline $\mathrm{T}_{\mathrm{g}, 2}(\mathrm{~K})$ & 360 \\
\hline $\mathrm{K}_{22}(\mathrm{~K})$ & 69.21 \\
\hline $\mathrm{C} 1$ & 11.01 \\
\hline $\mathrm{C} 2$ & 69.21 \\
\hline $\mathrm{k}\left(\mathrm{J} . \mathrm{K}^{-1}\right)$ & $1.38 \times 10^{-23}$ \\
\hline $\mathrm{a}(\mathrm{m})$ & $1 \mathrm{e}^{-9}$ \\
\hline
\end{tabular}

The remaining parameters are given by Vrentas, 1998:

$$
K_{22}=C_{2}
$$

and

$$
\frac{K_{12}}{\gamma}=\frac{\hat{V}_{2}^{*}}{2.303 C_{1} C_{2}}
$$

$\mathrm{C}_{1}$ and $\mathrm{C}_{2}$ are universal constants.

The self diffusivity of the solid particles $\left(D_{s}\right)$ follows from the Stokes-Einstein theory (Crank, 1968):

$$
D_{s}=\frac{k T}{6 \pi a \eta_{e f f}}
$$

Here, a $(\mathrm{m})$ is the radius of the solid particle, $\eta_{\text {eff }}$ (Pa.s) the viscosity, and $\mathrm{k}$ is the Boltzmann constant which is equal to $1.38 \times 10^{-23} \mathrm{~J} . \mathrm{K}^{-1}$.

The sorption isotherm relationship is used in the boundary conditions for mass transfer, which gives the diffusion of water to the surface and evaporation to the environment. Mulet et al. (1999) gave for broccoli the following measured relationship:

$$
a_{w}=1-\exp \left(-5.18 W^{0.93}\right)
$$

Mulet et al. (1999) observed also shrinkage during drying. Simal et al. (1998) suggested a shrinkage model which is based on a proportional change of the volume with the changes in moisture content. According their results, shrinkage only happens in radial direction.

$$
\frac{V}{V_{0}}=0.0649+0.0952 \mathrm{~W}
$$

\section{Degradation of healthy components}

As an indicator for components that contribute to health, vitamin $\mathrm{C}$ is considered. Degradation of vitamin $\mathrm{C}$ follows a first order degradation kinetics:

$$
\frac{d C}{d t}=-k C
$$

with $\mathrm{C}$ the concentration and $\mathrm{k}$ the rate constant $\left(\mathrm{s}^{-1}\right)$. The temperature dependency of $\mathrm{k}$ is given as:

$$
k=k_{0}\left(-\frac{E_{a}}{R T}\right)
$$

Mikshkin et al. (1984) and Karim et al. (2009) found the following expressions for the rate constant and activation energy of vitamin $\mathrm{C}$ degradation during hot air drying.

$$
\begin{gathered}
k_{0}=\exp \left(P_{1}+P_{2} W+P_{3} W^{2}\right) \\
E_{a}=P_{4}+P_{5} W+P_{6} W^{2}+P_{7} W^{3}
\end{gathered}
$$

With $\mathrm{P}_{1}-\mathrm{P}_{7}$ are the constants and $\mathrm{W}$ is the moisture content.

Table 3: Vitamin $\mathrm{C}$ degradation kinetic model parameter values for Eq. (21) and (22)

\begin{tabular}{|l|l|l|l|}
\hline Parameter & Value & Parameter & \multicolumn{1}{c|}{ Value } \\
\hline $\mathrm{P}_{1}$ & 16.38 & $\mathrm{P}_{4}$ & 14831.0 \\
\hline $\mathrm{P}_{2}$ & 1.782 & $\mathrm{P}_{5}$ & 241.1 \\
\hline $\mathrm{P}_{3}$ & 1.890 & $\mathrm{P}_{6}$ & 656.2 \\
\hline & & $\mathrm{P}_{7}$ & 236.8 \\
\hline
\end{tabular}

\section{RESULTS}

\section{Diffusion model for broccoli stalks}

The free volume theory model was used to compute the effective diffusion coefficient during diffusion controlled drying of broccoli stalks. Simulations were done using cylindrical stalks of length $0.02 \mathrm{~m}$ and radius $0.004 \mathrm{~m}$. These drying conditions and the sample sizes were the same as the work of Simal et al. (1998) and he estimated the effective diffusion coefficient values at $90^{\circ} \mathrm{C}$ between $1.63 \times 10^{-9}$ to $2.25 \times 10^{-9}\left(\mathrm{~m}^{2} . \mathrm{s}^{-1}\right)$ for different drying times $(720 \mathrm{~s}-$ 2160s) and positions by using the Arrhenius equation. The diffusion coefficient values based on free volume theory range from $1.56 \times 10^{-9}$ to $3.20 \times 10^{-9}\left(\mathrm{~m}^{2} \cdot \mathrm{s}^{-1}\right)$.

Further simulations with the free volume theory were done for the effective diffusion coefficient during drying of broccoli stalks. As the self-diffusion coefficient of water molecules is influenced by the moisture content, a full range of moisture contents was used. Fig.2 shows the results for different temperatures, ranging from 20 to $50^{\circ} \mathrm{C}$. The figure shows that the obtained diffusion coefficients vary with temperature and moisture content and are comparable to the literature results. At moisture contents, below $0.5 \mathrm{~kg}$ water per $\mathrm{kg}$ dry matter, the results deviate from the literature values. Here, the free volume theory predicts a lower diffusion coefficient because of the lower mobility of the water molecules. For the diffusion coefficient a maximum value is found for a moisture content of $2 \mathrm{~kg}$ water per kg dry matter. Furthermore, the graph shows that, just like the Arrhenius equation, the diffusion coefficient increases with raising temperature. 


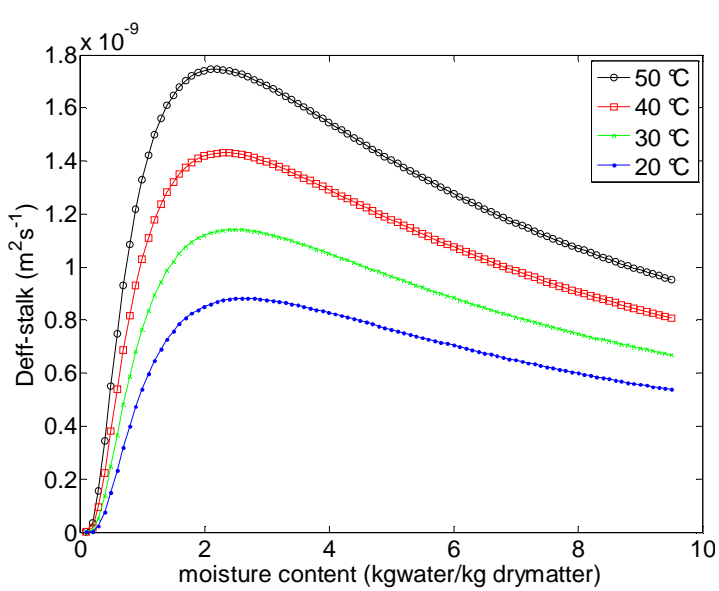

Fig2. Simulation results of effective diffusion coefficient of broccoli stalk at different temperatures. (top to bottom: $50^{\circ} \mathrm{C}, 40^{\circ} \mathrm{C}, 30^{\circ} \mathrm{C}, 20^{\circ} \mathrm{C}$ )

\section{Diffusion model for broccoli florets}

Similarly, the effective diffusion coefficient of drying of broccoli florets was calculated. In the simulations, a diameter of $0.04 \mathrm{~m}$ and an average porosity 0.2 was used for the florets. The self-diffusion coefficient of water molecules was calculated by using the free volume theory; for the self-diffusion coefficient of the solid matrix the Einstein-Stokes theory was used. The effective diffusion coefficient of water molecules was calculated by using the MaxwellEucken theory. Mulet et al. (1999) gave effective diffusion coefficients based on the Arrhenius theory for the temperature range $35-70^{\circ} \mathrm{C}$. Their reported values of the effective diffusion coefficient were in the range of $3.00 \times 10^{-8}$ to $6.23 \times 10^{-8}\left(\mathrm{~m}^{2} . \mathrm{s}^{-1}\right)$. The values of the effective diffusion coefficient according the free volume theory are lower and ranged from $0.86 \times 10^{-8}$ to $1.67 \times 10^{-8}\left(\mathrm{~m}^{2} . \mathrm{s}^{-1}\right)$ over the temperatures range between $35-70^{\circ} \mathrm{C}$.

Furthermore, the same simulations which have been done for broccoli stalks, was also done for broccoli florets for the whole range of moisture content and temperatures. The results are shown in Fig 3. The results are comparable with literature values, except for the low moisture content range. As a result of the lower water mobility the diffusion coefficient is low. Compared to the broccoli stalks, the simulations show for the broccoli florets a ten times higher value. This is result of the porous structure of floret in which the air pockets enhance diffusion.

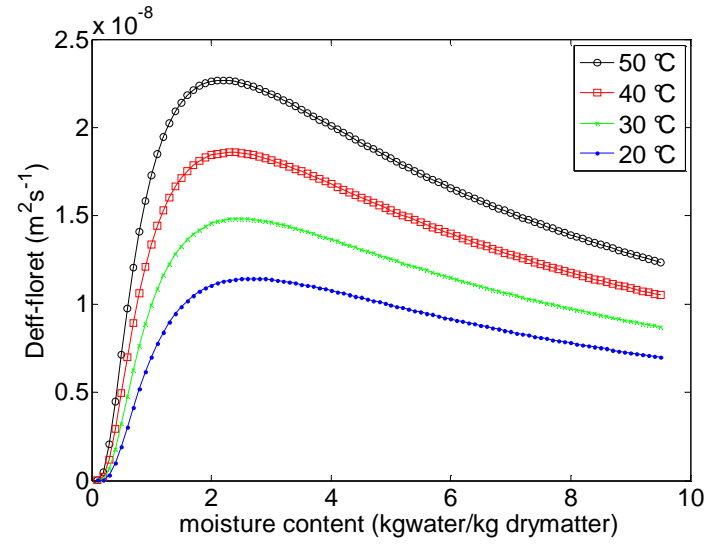

Fig 3. Simulation results of effective diffusion coefficient of broccoli floret at different temperatures. (Top to bottom: $50^{\circ} \mathrm{C}, 40^{\circ} \mathrm{C}, 30^{\circ} \mathrm{C}$, $\left.20^{\circ} \mathrm{C}\right)$

\section{Drying simulation results}

Dynamic drying simulations have been done in Comsol Multiphysics. A symmetric 2-D model was chosen according to the structure shown in Fig 1. The size of the simulation sample was $0.02 \mathrm{~m}$ in radius for the broccoli floret, $0.01 \mathrm{~m}$ in radius and $0.02 \mathrm{~m}$ in height for the broccoli stalk. The air temperature was set to $50^{\circ} \mathrm{C}$. To ensure diffusion controlled drying, the air flow rate was set to $2.5 \mathrm{~m} . \mathrm{s}^{-1}$. Shrinkage of the sample was included as well (see equation 18). The initial moisture content was set to $9.6 \mathrm{~kg}$ water per $\mathrm{kg}$ dry matter and was uniform distributed throughout the whole sample. The initial temperature of the product was $20^{\circ} \mathrm{C}$ i.e. the room temperature

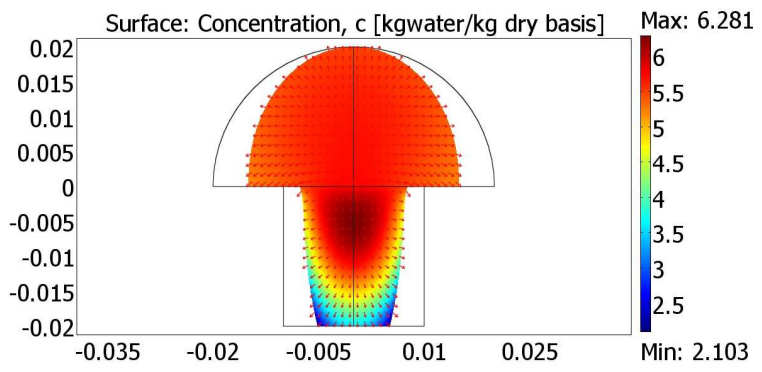

Fig 4 Spatial moisture distribution of broccoli at 10 hours of drying at $50^{\circ} \mathrm{C}$. Drying starts at the outer frame which changes due to shrinkage to the coloured frame.

Fig 4 shows the moisture distribution in broccoli after ten hours of drying. The colour surface gives the moisture distribution within broccoli. The temperature distribution was also calculated, but after ten minutes drying, the temperature profile was already equally distributed. The colour bar at the right of the graph gives the scale of moisture content. By comparing the colour in the frame and the colour bar, the value of moisture content can be read.

Also, from the figure, the moisture is seen to diffuse from the centre to the outer surface in the direction of 
the arrows. At the surface, moisture evaporates due to the mass and energy exchange with the air and the surface dries first. Moisture content increases towards the centre of the product. The product gradually shrinks during the drying process, and shrinkage is shown by comparing the current frame with the original frame.

Compared to the stalk, the moisture profile for the floret is more uniform. This phenomenon follows from the porous structure of the floret, which takes advantage of the diffusion properties of water in air.

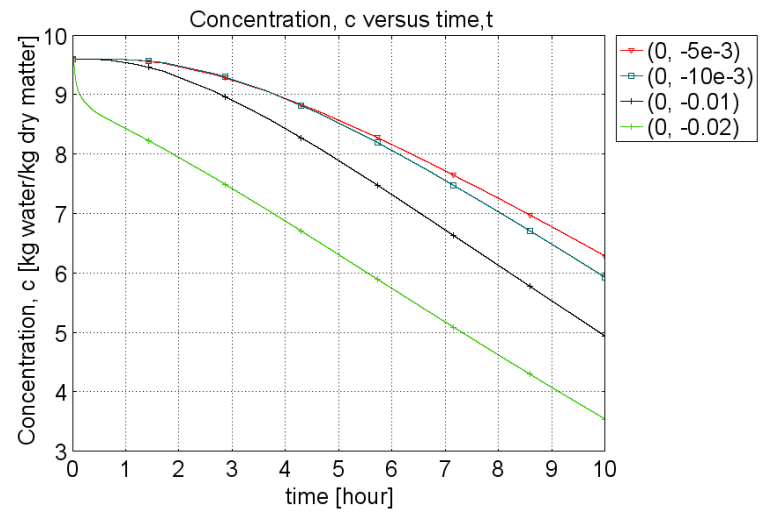

Fig 5 Drying curves of broccoli stalk with different positions from top to bottom on z-direction (indicated position in $\mathrm{m}$ )

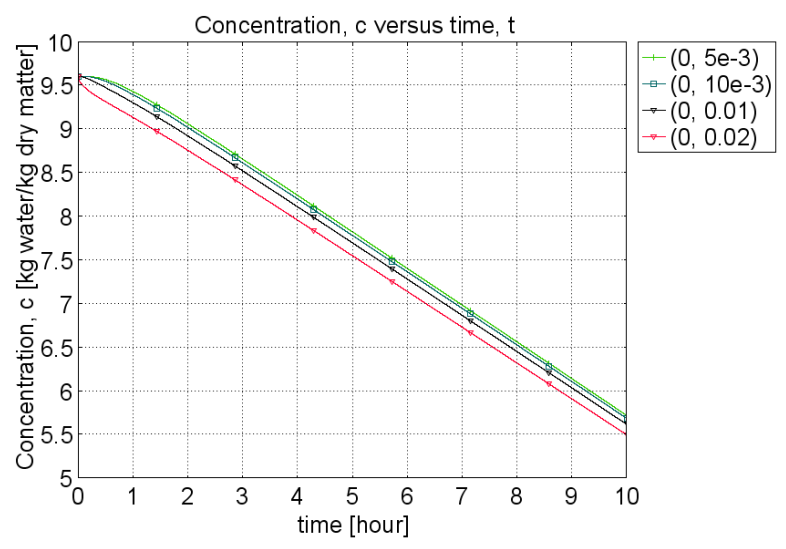

Fig 6 Drying curves of broccoli floret with different positions from bottom to top on z-direction (indicated position in $\mathrm{m}$ )

Simulation results for different positions are given in Figures 5 and 6 . Since the radius changes, the results were collected based on different z-values (height) for floret and stalk respectively. Each curve in Figures 5 and 6 indicate the local moisture variation in the drying time with different positions from the centre to the surface following the height of the cylinder and the radius of the floret in the $\mathrm{z}$-direction. The drying curves for the broccoli stalks are quite distinct for the different positions, the outer surface dries faster than the centre core. Whereas, the drying curves for broccoli florets are close for the different positions.

\section{Degradation of healthy components}

The rate constant for vitamin $\mathrm{C}$ degradation was estimated for the whole range of moisture contents and air drying temperature from $20-50{ }^{\circ} \mathrm{C}$. As shown in Fig 7, the degradation rate constant is a bell shaped curve. Above $4 \mathrm{~kg}$ water per $\mathrm{kg}$ dry matter, the degradation rate constant is very low and there is a maximum value at moisture content of $2 \mathrm{~kg}$ water per kg dry matter. The rate constants increase with increasing temperature.

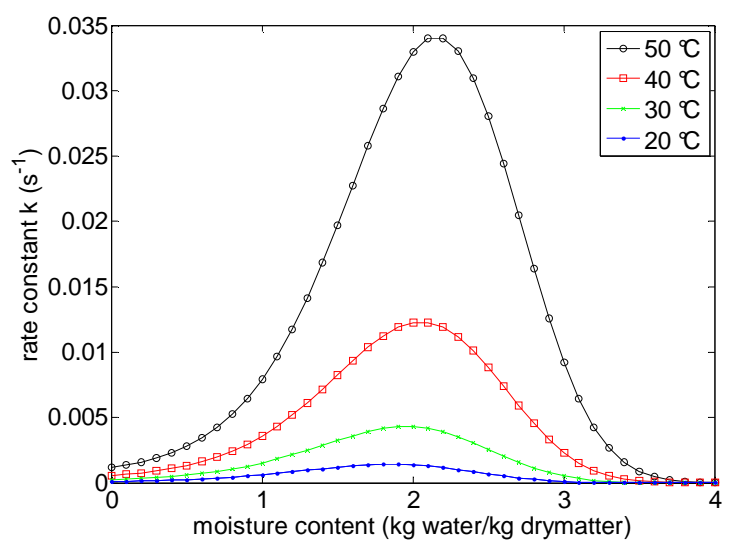

Fig 7 The relation between Vitamin C degradation rate constant and sample moisture content.

Simultaneous simulation of drying and vitamin C degradation was performed. The vitamin C concentration profiles are given in Fig 8. The top figure, for $\mathrm{t}=10$ hour, shows that at this moment degradation starts only at the bottom of the broccoli stalk. The whole broccoli floret and the major part of the broccoli stalk still have the initial concentration. At this moment, the moisture content in the major part of the broccoli is still above $4 \mathrm{~kg}$ water per $\mathrm{kg}$ dry mater, where vitamin $\mathrm{C}$ degradation hardly occurs.

Furthermore, Fig 8 shows also the concentration profiles at 15 hour and 16 hour drying. In this period, the moisture content of the whole body falls below a critical value and the degradation rate constant increases rapidly. As a result of these conditions, the vitamin $\mathrm{C}$ concentration decreases fast. At 15 hours, vitamin $\mathrm{C}$ concentration in the stalk is already low and the concentration starts to decrease in the floret. At 16 hours, there is hardly any Vitamin C left. 

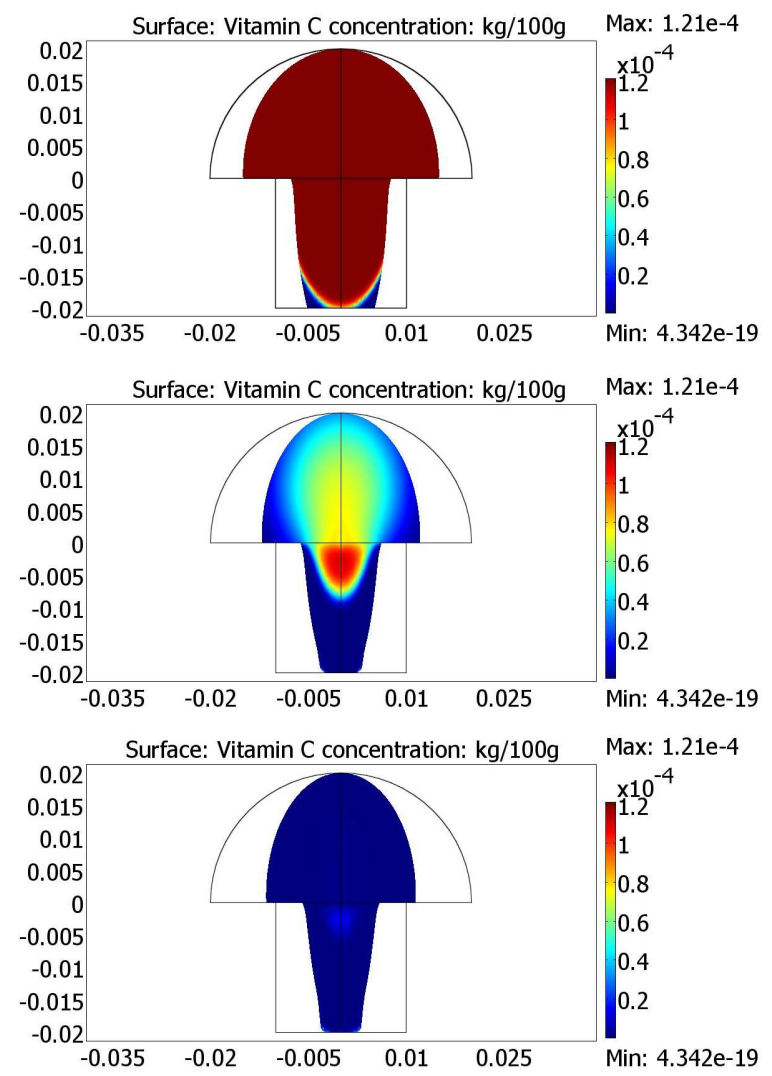

Fig.8. Vitamin C distribution throughout the sample. Top: after 10 hour drying, middle: after 15 hour drying, bottom: after 16 hour drying

\section{CONCLUSION}

In this paper, the free volume theory together with Maxwell-Eucken theory is used to predict the effective diffusion coefficient during drying of broccoli. The obtained values from the proposed model are close to the effective diffusion coefficient as given in the literature. Main advantage of the free volume theory is that the mobility of water molecules is taken into account and that the glass transition temperature is involved. This model has the potential to predict the effective diffusion coefficient more accurately over a wide range of moisture contents and temperatures. Besides, by combining the free volume theory with the Maxwell-Eucken theory, the moisture transport in the porous structure of broccoli floret can be predicted as well. For the prediction of moisture transport, general physical properties are used and the results are comparable with values given in the literature.

By using a spatial model, temperature and moisture distribution, as well as shrinkage is presented by the 2-D colour map and a moving mesh function. The temperature distribution in broccoli proved to be uniform after a relatively short time. During drying at $50^{\circ} \mathrm{C}$ the moisture distribution in the broccoli floret is homogeneous. The model used in this work is a good tool to predict the drying end point; especially for the low moisture contents. It has also potential for quality optimization. The simulations show that a long drying time is required to bring the broccoli moisture content to a level of $0.2 \mathrm{~kg}$ water per kg dry matter which is the level for longer shelf life. From an energy efficiency point of view, other heating resources should be considered to enhance the drying process.

The spatial calculations make it possible to estimate the healthy components (e.g. vitamin C) distribution in the product throughout time. The results indicated that at high moisture contents $(>4 \mathrm{~kg}$ water per $\mathrm{kg}$ dry matter) the rate constant is minimal and degradation hardly occurs. However, the degradation rate is high at a moisture content of $2 \mathrm{~kg}$ water per $\mathrm{kg}$ dry matter. So optimization towards optimal drying paths to restrict degradation is required.

\section{ACKNOWLEDGEMENT}

This work is supported by the Energy Research Program EOS (EOS LT07043) of the Dutch Ministry of Economics.

\section{REFERENCE}

Bertoly, N., Chaves, A. and Zaritzky, N.E., 1990. Diffusion of carbon dioxide in tomato fruits during cold storage in modified atmosphere. International Journal of Food Science and Technology, 25(3): 318-327.

Bon, J., Simal, S., Rosselló, C. and Mulet, A., 1997. Drying characteristics of hemispherical solids. Journal of Food Engineering, 34(2): 109-122.

Crank, J., Park, G.S., Diffusion in Polymers, London: Academic Press, 1968

Hahn, H., Averback, R.S. and Rothman, S.J., 1986. Diffusivities of $\mathrm{Ni}, \mathrm{Zr}, \mathrm{Au}$, and $\mathrm{Cu}$ in amorphous Ni-Zr alloys. Physical Review B, 33(12): 8825.

He, X.M., Fowler, A., and Menze, M., 2008. Desiccation Kinetics and Biothermodynamics of Glass Forming Trehalose Solutions in Thin Films. Annals of Biomedical Engineering, 36(8): 14281439.

Hong, S.-U., 1996. Predicting ability of free-volume theory for solvent self-diffusion coefficients in rubbers. Journal of Applied Polymer Science, 61(5): 833-841.

Karim, O.R. and Adebowale, A.A., 2009. A Dynamic Method for Kinetic Model of Ascorbic Acid Degradation during Air Dehydration of Pretreated Pineapple Slices. International Food Research Journal, 16: 555-560

Mishkin, M., Saguy, I. and Karel, M., 1984. Optimization of Nutrient Retention During Processing: Ascorbic Acid in Potato Dehydration. Journal of Food Science, 49(5): 1262-1266. 
Mulet, A., Sanjuan, N.and Bon, J., 1999. Drying Model for Highly Porous Hemispherical Bodies/ European Food Research and Technology, 210:80-83.

Nasrabad, A.E., Laghaei, R. and Eu, B.C., 2005. Modified Free Volume Theory of Self-Diffusion and Molecular Theory of Shear Viscosity of Liquid Carbon Dioxide. The Journal of Physical Chemistry B, 109(16): 8171-8179.

Olek, W.a., Perre, P. and Weres, J., 2005. Inverse analysis of the transient bound water diffusion in wood. Holzforschung, 59(1): 38-45.

Saguy, I., Kopelman, I.J. and Mizrahi, S., 1978. Simulation of Ascorbic Acid Stability During Heat Processing and Concentration of Grapefruit Juice. Journal of Food Process Engineering, 2(3): 213-225.

Simal, S., Rosselló, C., Berna, A. and Mulet, A., 1998. Drying of shrinking cylinder-shaped bodies. Journal of Food Engineering, 37(4): 423435.

Vrentas, J.S. and Duda, J.L., 1977. Diffusion in polymer - solvent systems. I. Reexamination of the free-volume theory. Journal of Polymer Science: Polymer Physics Edition, 15(3): 403416.

Vrentas, J.S. and Vrentas, C.M., 1994. Evaluation of a sorption equation for polymer-solvent systems. Journal of Applied Polymer Science, 51(10): 1791-1795.

Vrentas, J.S. and Vrentas, C.M., 1998. Predictive methods for self-diffusion and mutual diffusion coefficients in polymer-solvent systems. European Polymer Journal, 34(5-6): 797-803. 